\title{
Isis a través de los textos: el culto isíaco en la literatura grecolatina de época altoimperial
}

\author{
Israel SANTAMARÍA CANALES \\ Universidad de Cádiz \\ israel.santamariacanales@gmail.com
}

\section{RESUMEN}

El culto a la diosa Isis, de origen egipcio aunque helenizado a partir del dominio macedónico, se expande por el mundo grecorromano hasta abarcar un espacio geográfico muy amplio, como nunca antes había conocido. Los testimonios literarios que se refieren a él en época altoimperial son abundantes y de distinta naturaleza, desde descripciones precisas de elementos clave hasta escritos hostiles por parte de autores cristianos con una intencionalidad muy clara. El análisis pormenorizado de estos textos se antoja necesario si se quiere llegar a conocer el estado en el que se encuentra el culto isíaco en un período como el Alto Imperio.

Palabras clave: Isis, culto isíaco, Imperio romano, cultos mistéricos, fuentes literarias.

\section{Isis through the texts: The Isiac cult in Greco-Roman literature of the Principate}

\begin{abstract}
The cult of the goddess Isis, of Egyptian origin but hellenized from Macedonian rule, expands around the Greco-Roman world to cover a wide geographical area, as it had never known before. The literary evidence that reference to it in the Principate are plentiful and of a different nature from accurate descriptions of key elements to hostile writings by christian authors with a clear intention. The detailed analysis of these texts seems necessary if you want to get to know the state in which is located the cult of Isis in the first three centuries of the Roman imperial period.
\end{abstract}

Keywords: Isis, Isiac Cult, Roman Empire, Mystery Cults, Literature Sources.

SUMARIO: 1. Introducción. 2. Breve historia de Isis y su culto. 3. El culto isíaco en la literatura grecolatina de época altoimperial. 3.1. Plutarco y Apuleyo, los autores de referencia. 3.2. La diosa del Nilo en los dominios del Tíber. 3.3. La presencia de Isis en la historiografía grecorromana. 3.4. El culto isíaco y sus feligreses (y feligresas). 3.5. De errores y críticas. 3.6. Otros puntos de interés. 4. Conclusiones. 5. Fuentes. 6. Bibliografía.

FECHA DE RECEPCIÓN: 31 DE 01 DE 2015 FECHA DE ACEPTACIÓN: 24 DE 04 DE 2015

\section{INTRODUCCIÓN}

Muy atrás han quedado aquellos tiempos en los que los historiadores, al más puro estilo del academicismo decimonónico rankeniano, nos limitábamos a sumergirnos en las profundidades de los escritos relativos a la misma época que tratábamos de co- 
nocer. De este modo, si un investigador se propone estudiar la política económica de un emperador romano determinado (es un decir), probablemente solo podría contar con las obras apologéticas surgidas por y para el elogio del poder de turno, o con las críticas más feroces perpetradas a posteriori por los detractores del monarca caído en desgracia y condenado a la correspondiente damnatio memoriae. Como dijo Woody Allen, «toda objetividad es subjetiva», y si a veces esta máxima sigue teniendo cabida en nuestra disciplina en pleno siglo XXI, cómo no va a ser así en los escritos de unos autores al servicio de la élite imperial e inmersos en el complejo entramado de intrigas y ambiciones que constituyó el Imperio romano.

Hoy en día, prácticamente nadie entiende la Historia como una lectura repetitiva hasta el hartazgo de los documentos oficiales y las crónicas más o menos fiables de autores clásicos como Heródoto, Tucídides o Polibio. La historiografía ha avanzado a pasos de gigante con el transcurrir de los años, entre otras cosas debido a enfoques novedosos, a avances significativos en la praxis del estudio histórico, al notable incremento del rigor científico, a la cantidad de información que ha arrojado y arroja la Arqueología, y a planteamientos interdisciplinares con otras ramas del saber que resultan de lo más fructíferos. No obstante, la literatura y los tratados históricos, filosóficos o religiosos con siglos de edad a sus espaldas siguen teniendo un valor incalculable que no debe ser desdeñado, al tratarse del reflejo más directo que ha llegado hasta nuestros días de una mentalidad remota. O más bien convendría hablar de mentalidades, con sus distintas filias, fobias e intereses particulares que han quedado impresos de por vida.

Esto es lo que queremos trasladar aquí en relación con nuestro objeto de estudio, que no es otro que la presencia de la diosa Isis y sus seguidores en la Roma de los siglos I a. C. - III d. C. Para ello, recabaremos los distintos comentarios, anécdotas y opiniones de los intelectuales del momento que, por un motivo u otro, dedicaron algo de su atención a esta divinidad egipcia que gozó de una proyección cuasi universal. Salvo excepciones puntuales como Plutarco o Apuleyo, las referencias son escasas y por lo general de poca importancia, pero analizadas con perspectiva y con una división temática apropiada se puede sacar mucho jugo a estas alusiones a una deidad extranjera que, no conviene olvidarlo, resultaba sospechosa, excéntrica y ajena al paganismo tradicional romano. El objetivo de este artículo consiste, pues, en ofrecer una panorámica o visión de conjunto de la imagen de Isis en el período que los historiadores hemos denominado Alto Imperio.

\section{BREVE HISTORIA DE ISIS Y SU CULTO}

En la cosmogonía heliopolitana ${ }^{1}$, Isis ${ }^{2}$ era la hija de Geb, dios de la tierra, y Nut, diosa del cielo, y hermana de Osiris (de la que también fue esposa), Seth y Neftis.

\footnotetext{
1 Armour, 2006, pp. 55-59.

${ }^{2} \mathrm{Su}$ nombre original egipcio era Ast, que literalmente quiere decir «trono». Isis es el nombre con el que la conocen los griegos.
} 
Una de sus principales atribuciones es su papel como madre, algo que queda perfectamente reflejado en infinidad de representaciones en las que ella aparece amamantando a Horus o a Harpócrates (Horus niño). Su relación con el resto de divinidades del panteón egipcio no se queda ahí, y así por ejemplo crió como a su propio hijo al dios chacal Anubis (hijo de Osiris y Neftis), colaboró con el dios con cabeza de ibis Thot en el proceso de resurrección de su hermano y esposo, utilizó sus dotes para el engaño y la magia para conocer el verdadero nombre de un anciano Ra, e incluso en algunas variaciones del mito combatió contra su hermano Seth. Fue una divinidad eminentemente polifacética, que iba adquiriendo más y más atribuciones conforme asimilaba las características de otras diosas como Neftis ${ }^{3}$, Hathor ${ }^{4}$ o Maat.

Aunque se haya perdido para siempre, el culto gestado en torno a su figura tiene más de tres milenios de historia. Su origen data de la Dinastía V de Egipto (en torno al 2500-2350 a. C.) y perdura hasta que, en el año $535^{5}$, el emperador Justiniano ordena la clausura del iseo de la isla egipcia de Filé. Tras este hecho, el culto isíaco desaparece de la historia oficial, aunque sobrevive en el ámbito privado hasta al menos el siglo VIII. Un punto de inflexión en la evolución de este movimiento religioso lo marca la implantación en el país del Nilo de la dinastía Ptolemaica o Lágida, instaurada por el general Ptolomeo tras la muerte de Alejandro Magno ${ }^{6}$. Isis se ve favorecida por la política que adopta el primero de los faraones de lengua griega ${ }^{7}$, y es entonces cuando empieza a convertirse en la deidad helenizada que desembarca en la Península itálica y se expande por todo el mundo mediterráneo en compañía de su paredro, la divinidad de nuevo cuño que conocemos como Serapis ${ }^{8}$.

Isis contaba ya con un núcleo religioso bastante fuerte en el Ática, sobre todo en Atenas y El Pireo ${ }^{9}$, ciudades en las que se adoraba a la diosa desde el siglo V a. C. de un modo similar al de los misterios eleusinos consagrados a Démeter y Perséfone ${ }^{10}$. El culto se expande por toda la Hélade con la excepción del Peloponeso, así como en las islas griegas y la costa del Mar Negro. Donde gozó de un mayor grado de aceptación fue en Delos, enclave que mantenía relaciones de índole comercial con la Magna Grecia, por donde se supone que el culto isíaco penetra en la República romana entre los siglos II y I a. C., un período marcado por profundos cambios de mentalidad y transformaciones estructurales. El culto prospera en la propia Roma y se llega incluso a erigir estatuas y altares de divinidades nilóticas en el mismo Capitolio, lo que provoca

\footnotetext{
${ }^{3}$ Normalmente se establecía una contraposición dual entre ambas, y así por ejemplo Isis representaba la vida o el día y Neftis la muerte o la noche, aunque a la larga la primera también se quedó con el campo de acción de esta última.

${ }^{4}$ A esta diosa pertenecían originariamente los cuernos de vaca y el disco solar que con posterioridad aparecrían en las representaciones de Isis, un claro caso de asimilación de atributos por parte de otra divinidad que no sería ni mucho menos exclusivo del ámbito egipcio.

${ }^{5}$ Baring-Cashford, 2005, p 661.

${ }^{6}$ Grimal, 1982a, p. 184.

${ }^{7}$ Radford Ruether, 2005, pp. 61-69.

${ }^{8}$ Husain, 2006, pp. 32-33.

9 Plácido Suárez, 1996, pp. 2-11.

${ }^{10}$ Puech, 1982, pp. 68-76.
} 
conflictos con el Senado que desembocan en persecuciones, demoliciones y acciones violentas que culminan en la abolición oficial del culto en época tardorrepublicana ${ }^{11}$.

La presión de sus devotos hace que se dé marcha atrás a esta postura, pero el curso de los acontecimientos lo cambia todo: Cleopatra VII, la última Lágida, se erige a sí misma como nueva Isis ${ }^{12}$, por lo que la derrota de esta reina y Marco Antonio a manos de Octavio supone para el culto a Isis un nuevo revés en favor del paganismo tradicional romano. Las mujeres son las encargadas de mantener activa esta religión durante el tránsito de la República al Imperio, momento a partir del cual el isismo es beneficiado u hostigado por el poder estatal en función de quién sea el emperador. A título de ejemplo, señalar que Calígula, Nerón, Otón, Cómodo o Severo Alejandro, entre otros, se muestran favorables y lo apoyan, lo que contrasta con actitudes hostiles como las de César Augusto o Tiberio ${ }^{13}$. El culto llega bastante debilitado al siglo IV y, en el 391, el emperador Teodosio declara ilegal cualquier culto que no fuese el cristianismo niceno ${ }^{14}$.

Los restos arqueológicos conservados de naturaleza isíaca se pueden registrar en la práctica totalidad de la geografía del Imperio romano, lo que da buena muestra del nivel de expansión que alcanzó el culto. Italia, Hispania, Galia, Britania, Germania, Iliria, Macedonia, Grecia, Asia Menor, Egipto o Mauritania, son solo algunos de los territorios en los que se asentó ${ }^{15}$, alcanzando un mayor o menor grado de aceptación en función del caso. La epigrafía, la numismática o la papirología aportan sustanciosa información sobre este tema, tanto a nivel general como en aspectos más concretos como pueden ser las innumerables advocaciones de la diosa (como por ejemplo las de Isis Miriónima ${ }^{16}$, Isis Pelagia ${ }^{17}$ o Isis Faria ${ }^{18}$ ) o las deidades que acompañaban a esta en función del emplazamiento del que hablemos. Sin embargo, las fuentes literarias de autores griegos y latinos del Imperio romano siguen siendo fundamentales para conocer el culto isíaco, por lo que aquí nos centraremos en ellas.

\section{EL CULTO ISÍACO EN LA LITERATURA GRECOLATINA DE ÉPOCA ALTOIMPERIAL}

En los primeros pasos de nuestra era el paganismo tradicional romano se encuentra en una profunda crisis, lo que permite el arraigo y proliferación de cultos

\footnotetext{
${ }^{11}$ El culto a Isis se prohíbe en los años 59, 58, 53, 50 y 48 a. C. Los altares isíacos son destruidos sin más aunque, de nuevo, son restaurados por la piedad popular.

12 Grimal, 1982 b, p. 204.

13 Puech, 1982, pp. 68-76.

14 Padró, 1996, p. 436. Para la política religiosa de Teodosio, vid. Piganiol, 1972, pp. 237 ss.

15 Para más información sobre la expansión del culto isíaco en los dominios del Imperio romano, vid. Bricault, París, 2001

${ }^{16}$ La de los diez mil nombres.

17 Nuestra señora de las olas.

${ }^{18}$ Faria por su profunda vinculación con el Faro de Alejandría, una de las siete maravillas del mundo antiguo. Por su especial importancia para la navegación, es un elemento arquitectónico indispensable en la composición de esta famosa ciudad egipcia.
} 
mistéricos o de salvación ${ }^{19}$, entre los que figuraría el isismo ${ }^{20}$. Estos credos de procedencia oriental allanarán el camino facilitando el posterior triunfo del cristianismo ${ }^{21}$, lo que paradójicamente culminará con su abolición en detrimento de la religión triunfante ${ }^{22}$. Resultan numerosos los autores grecolatinos que se hacen eco de la presencia de la diosa Isis, algo que queda reflejado en una ingente cantidad de textos que, con más o menos acierto, ofrecen su propia visión del asunto. Mucho antes de la instauración del Imperio romano podemos encontrar nombres como el de Heródoto de Halicarnaso (s. V a. C.) para subrayar que el interés por lo isíaco venía de lejos y no es un fenómeno que surge de la nada junto al principado de César Augusto.

En época altoimperial, que es el período que aquí abarcamos, son muchos los que se ocupan de esta materia. Aunque cada autor lo haga a su modo, se dan una serie de coincidencias temáticas que nos permiten agrupar sus referencias en compartimentos estancos, más o menos delimitados, en función de los detalles que preocupaban a estos intelectuales. Sería un error dar por hecho que dichos historiadores, poetas y filósofos reflejan en sus escritos la opinión a pie de calle del populacho romano hostil al culto isíaco, pero necesariamente sí que deben transmitir algunas de las razones por las que Isis no fue del todo aceptada por la ciudadanía más conservadora. Conviene recordar que no es la misma la imagen popular de la diosa y su culto en la Roma de Augusto que en los siglos II y III, fechas de máximo auge de los cultos nilóticos, cuyas divinidades llegaron incluso a ser integradas en el panteón oficial. Asimismo, también por estos siglos comienzan las enconadas críticas por parte del cristianismo.

Es una etapa que se abre con la marginación del culto y su diosa a manos del princeps que acababa de convertir Egipto en una provincia de su propiedad, actitud que sigue vigente en su sucesor Tiberio. Se oscila entre repuntes de esa marginación impuesta y paréntesis en los que emperadores favorables a su desarrollo adoptan medidas tales como la reconstrucción de iseos o la añadidura de festivales isíacos al calendario romano. Es durante el reinado de Caracalla cuando podemos afirmar sin miedo a equivocarnos que Isis ya no fue considerada nunca más como una divinidad extranjera, aunque la muerte de este monarca será la que marque directa o indirectamente el principio del fin de su esplendor, dejando entrever la suerte que correrán ella y su culto en un futuro no muy lejano. Isis y Serapis no volverían a ser marginados por la población hasta el triunfo de los cristianos, pero tampoco gozarán del favor de los poderosos como sí había ocurrido anteriormente en determinados casos.

\footnotetext{
${ }^{19}$ Obligatoria referencias para iniciarse en el estudio y la comprensión de los cultos mistéricos en el mundo mediterráneo son Turcan, 2001 y Burkert, 2005. Para el caso concreto del culto isíaco, se recomienda Witt, 1997; Donalson, 2003 y Bricault 2013.

${ }^{20}$ Lozano, 2007, p. 117.

${ }^{21}$ Puech, 1982, pp. 92-93.

22 Alvar y Martínez Maza, 2007, pp. 528-536.
} 


\subsection{PLUTARCO Y APULEYO, LOS AUTORES DE REFERENCIA}

En primer lugar, el polifacético Plutarco de Queronea (46-120 d. C.) es una de las principales fuentes para el conocimiento de Isis y el culto isíaco en el Imperio romano junto a El asno de oro de Apuleyo de Madaura. Más que un pasaje, conviene leer por completo su tratado Sobre Isis y Osiris incluido en sus Obras morales y de costumbres o Moralia, un auténtico compendio del saber en el que además se incluye la versión más completa que se conserva del mito de Isis y Osiris, aunque sea en una variante helenizada que se asemeja en más de un aspecto al mito griego de Démeter y Perséfone, con el que guarda no pocos paralelismos. Tanto por lo información que ofrece sobre la diosa y su culto como por el alto valor sincrético de su obra, en la que se pueden ver perfectamente amalgamadas la tradición milenaria del Antiguo Egipto con la concepción espiritual del mundo grecorromano, se debe valorar el conjunto de este tratado al ser un pilar central de nuestro objeto de estudio ${ }^{23}$.

Como antes apuntamos, El asno de oro del norteafricano Apuleyo de Madaura (123-180 d. C.) es la piedra angular de las fuentes literarias sobre el isismo junto al ya mencionado tratado de Plutarco. Es en el tramo final de la novela donde la diosa Isis y su culto adquieren especial relevancia: la devoción isíaca del protagonista, Lucio, convertido en asno por un encantamiento mágico, será la que le permita recuperar su forma humana, tras lo cual optará por ingresar en la congregación. En la obra se describe el proceso de la iniciación en el culto isíaco con todo lujo de detalles. Al igual que ocurría con Sobre Isis y Osiris, es absurdo hacer una selección de un libro que conviene leer de principio a fin (en este caso, tanto por la información que arroja sobre infinidad de aspectos de la sociedad romana como por su calidad literaria y el entretenimiento que ofrece al lector) o, en el caso del culto a Isis, como mínimo el Libro XI en su totalidad.

El hecho de que el propio Apuleyo probablemente fuese un seguidor de la diosa no hace sino acrecentar la valía de su relato, aunque esto pudo ser el principal desencadenante de que nos deje con la miel en los labios cuando tiene que tratar los últimos pasos del ritual. Debido al voto de silencio que ataba de pies y manos a los iniciados, el escritor interrumpe en seco la narración en el tramo en el que le tocaba describir el desenlace de la ceremonia, lo que hasta la fecha nos ha impedido saber qué ocurría en lo más profundo del iseo, dejados atrás los umbrales de Prosepirna, cuando el fiel renacía a una nueva vida entregada al servicio de los dioses del Nilo. Son muchos los detalles relativos al culto a Isis sobre los que Apuleyo arroja luz, tales como el peso que adquiría la incubatio en la liturgia isíaca, las procesiones isíacas o la certificación de que el dinero abría muchas puertas en el seno de este culto. En definitiva, El asno de oro es imprescindible en todos los sentidos para nuestro cometido $^{24}$.

\footnotetext{
23 Para más información sobre Isis y su culto en la obra de Plutarco vid. Hani, 2005, pp. 125-141.

${ }^{24}$ Para más información sobre Isis y su culto en la obra de Apuleyo vid. Hidalgo de la Vega, 1986.
} 


\subsection{LA DIOSA DEL NILO EN LOS DOMINIOS DEL TÍBER}

Isis no es solo una divinidad maternal y protectora que procura el bienestar de sus fieles, sino que cuenta también con una cara terrible que saca a relucir cuando se siente ultrajada, algo que caracteriza a no pocas deidades femeninas del mundo antiguo que, entre sus prerrogativas, contaban campos aparentemente antagónicos como la vida y la muerte, la luz y la oscuridad o el amor y la guerra, entre las que destacan Astarté o Tanit, entre otras. El célebre Ovidio (43 a. C.-17 d. C.) alude en Pónticas a la capacidad de esta deidad para castigar con la privación de la vista a aquellos que la han ofendido o insultado ${ }^{25}$, un encantamiento que solo puede ser disuelto tras la correspondiente reconciliación ${ }^{26}$. Esta capacidad para provocar ceguera a los que desatan su ira también aparece recogida en las Sátiras ${ }^{27}$ de Juvenal (60-128 d. C.), solo que aquí aparece bajo su particular sentido del humor, ácido e hiriente, al igual que cuando alude a la presunta relación entre Isis y los artistas (concretamente los pintores) y a la vertiente salutífera de la diosa ${ }^{28}$.

Algo que resulta de lo más curioso es la constante asimilación que se establece entre Isis e Í ${ }^{29}$, hija de Ínaco, una asimilación que, sobre todo en época imperial, es más común de lo que cabría esperar. Este paralelismo figura en dos obras de Ovidio, concretamente en Tristes $^{30}$ y en Amores $^{31}$, así como en Farsalia ${ }^{32}$ de Lucano (39-65 d. C.), poeta de origen cordobés y sobrino de Séneca. Apolodoro (s. II d. C.), en su manual de mitología grecorromana conocido como Biblioteca o Biblioteca mitológica, vuelve a establecer la consabida comparación entre sendos personajes femeninos $^{33}$, lo que nos invita a pensar que se trata de un proceso más que aceptado según se extrae de los testimonios que se ocupan de esta cuestión. Al igual que Plutarco consiguió aunar la tradición helénica y la egipcia con su particular versión del mito de Isis y Osiris en relación a Démeter y Perséfone, pudo producirse un proceso de hibridación similar entre una de las muchas amantes del olímpico Zeus y la diosa del Nilo.

El escritor de origen sirio Luciano de Samósata (125-181 d. C.), menciona puntualmente a Isis en siete de sus obras, concretamente en El sueño o el gallo ${ }^{34}$, Con-

\footnotetext{
25 Ou. Pont. I, 51-59.

${ }^{26}$ Existía la creencia popular de que Isis castigaba a los perjuros con la ceguera. No sabemos si esto es una superstición fruto del desconocimiento o del miedo a lo desconocido.

27 Iuv. XIII, 90.

${ }^{28}$ Iuv. XII, 25-35.

29 Ío fue convertida en vaca por Júpiter para librar a esta de la cólera de Juno, para luego ser azuzada por un tábano enviado por la celosa esposa del padre de los dioses y los hombres. En su nueva forma recorrió muchos lugares, dando nombre al mar Jónico (o mar de Ío) y al Bósforo o paso de las vacas. Finalmente recabó en Egipto donde, devuelta a su forma humana, fue venerada bajo el nombre de Isis.

30 Ou. Trist. II, 298-299.

31 En varias ocasiones se alude a Isis pero siempre como Ío, hija de Ínaco, vaca de Menfis o ternera de Faros, de ahí que no se incluyan dichas referencias en el artículo.

32 Lucan. VI, 360-365.

33 Apollod. II, 3.

34 Luc. Gall. 18.
} 
tra un ignorante ${ }^{35}$, El aficionado a la mentira ${ }^{36}$, Podagra $^{37}$, El barco $^{38}$, Diálogos de los dioses ${ }^{39} \mathrm{y}$, en sus Epigramas ${ }^{40}$. Son apuntes marginales en los que se incide, sobre todo, en las vertientes mágica y marítima de la diosa, así como en su asimilación con Ío. Uno de los más reputados escritores eclesiásticos de la Iglesia primitiva, Hipólito de Roma (170-236 d. C.), dice en su Refutación de todas las herejías que el pueblo egipcio es el más arcaico de cuantos existen en este mundo, siendo solo superados en antigüedad por el de los frigios. De los egipcios dice, entre otras cosas, que estos poseen los misterios de Isis, afirmando que la razón del ser del mismo se basa en la búsqueda por parte de la diosa de los siete mantos negros del miembro fálico de su difunto esposo ${ }^{41}$; también la incluye luego en el fragmento de un tratado perático ${ }^{42}$.

\subsection{LA PRESENCIA DE ISIS EN LA HISTORIOGRAFÍA GRECORROMANA}

A continuación, vamos a hablar de los episodios de carácter histórico o pseudohistórico en los que Isis desempeña un rol protagonista o secundario, algo que también afecta a determinados emperadores romanos que aparecerán más abajo. El escritor judío Flavio Josefo (37-101 d. C.) hace hincapié en Contra Apión en otra virtud muy característica de la diosa: la de manifestarse en los sueños de un individuo. En este caso, lo hace ante un faraón llamado Amenofis, padre de Ramsés, al que transmite un mensaje determinado que no es de interés para nuestros propósitos ${ }^{43}$, un hecho que se repite aunque en un tono muy distinto en la querella entre Manetón y Queremón ${ }^{44}$; en ambos casos se resalta uno de los máximos distintivos isíacos, su dominio del plano onírico. En La guerra de los judios ${ }^{45}$ menciona el episodio de Vespasiano y Tito en el iseo situado junto al Campo de Marte, algo que recogen otros autores y que no deja de ser una simple anécdota.

Las Vidas de los doce césares del biógrafo Suetonio (70-126 d. C.) tampoco olvidan a la madre de Horus y albergan dos referencias que, curiosamente, están enmarcadas en el período de guerras civiles que conocemos como el año de los cuatro emperadores. En la primera de ellas dice que Otón celebraba en público el culto isíaco, que se depilaba el cuerpo y que a veces aparecía ataviado con el traje

\footnotetext{
35 Luc. Ind. 14.

${ }^{36}$ Luc. Philops. 34.

37 Luc. Trag. 50.

${ }^{38}$ Luc. Nav. 5; 14-15.

${ }^{39}$ Luc. DDeor. 7.

${ }^{40}$ Luc. $A P . \mathrm{X}, 32$.

41 Hippol. Haer. V, 7, 22-23.

${ }^{42}$ Hippol. Haer. V, 14, 6.

43 F. Ap. I, 32, 288-290.

44 F. Ap. I, 33, 294-300.

45 F. BJ. VII, 121-131.
} 
de lino ${ }^{46}$; en la segunda, refiere cómo el futuro emperador Domiciano, junto a su tío Sabino, se escondieron en el Capitolio durante la guerra con Vitelio y, cuando el templo fue pasto de las llamas, lograron salvar sus vidas al disfrazarse de sacerdotes de Isis y camuflarse entre los seguidores de la diosa ${ }^{47}$. También recoge la prohibición por parte de Augusto de cultos egipcios y judíos, sin mencionar eso sí el nombre de Isis en ningún momento ${ }^{48}$. Son pequeñas pinceladas que, por ejemplo, nos permiten elucubrar qué habría sido del culto isíaco si Otón hubiese aguantado más en el poder.

Por su parte, Apiano (95-165 d. C.) habla en la Historia romana de un enfrentamiento entre el rey del Ponto, Mitrídates IV, y el pueblo de los rodios, un asedio en el que tiene un papel protagonista una máquina de guerra llamada «sambuca» que estaba ubicada junto a un iseo, y cuando el artilugio es derribado por los rodios, Apiano afirma que fue como si la propia Isis arrojara fuego sobre él ${ }^{49}$. En uno de sus volúmenes dedicado a las Guerras Civiles de Roma, narra la huida de un tal Volusio, edil partidario de Pompeyo, que logró escapar gracias a la ayuda de un sacerdote de Isis que le cedió su indumentaria y una máscara de perro ${ }^{50}$, lo que le permitió reunirse con su general ${ }^{51}$. Por último, Flavio Arriano (86-175 d. C.), refiere en su Anábasis de Alejandro Magno la fundación de una nueva ciudad por parte del monarca macedónico, que delimita cómo será la urbe con una precisión milimétrica y afirma que no solo los dioses griegos serán venerados en ella, sino también la egipcia Isis ${ }^{52}$.

\subsection{EL CULTO ISÍACO Y SUS FELIGRESES (Y FELIGRESAS)}

Una de las facetas en las que más se insiste cuando aluden al culto isíaco como tal es su absoluta inutilidad, algo lógico hasta cierto punto en una sociedad tan pragmática como la romana que entendía la religión como un mero do ut des. El primero en figurar aquí es el poeta lírico Tíbulo (54-19 a. C.) que, en sus Elegías, se dirige a una mujer llamada Delia, probable devota del culto, y le reprocha la inutilidad de sus creencias y las prácticas religiosas que lleva a cabo ${ }^{53}$, pregúntadose a sí mismo de qué le sirve a él tanto la propia Isis como el acto fútil de agitar los sistros ${ }^{54}$ en honor de la diosa. Lucano aporta en Farsalia dos menciones de interés en clave de recriminación

46 Suet. Otho. VII, 12.

47 Suet. Dom. VIII, 2.

48 Suet. Tib. III, 36.

49 App. Mith. XII, 27.

50 En las procesiones en honor de la diosa Isis los sacerdotes vestían delantales de lino y llevaban la cabeza rapada, mientras uno de ellos aparecía portando una máscara de perro o chacal en representación del dios Anubis.

51 App. BC. IV, 47.

52 Arr. An. III, 5.

53 Tib. I, 3, 23-34.

${ }^{54}$ Instrumento musical, similar a un sonajero, que constituye uno de los elementos más característicos del isismo en general y de algunas de sus festividades y procesiones en particular. 
en la que el autor reprocha a Roma la aceptación de cultos extranjeros como el isismo $\mathrm{y}$, por el contrario, no rinde el homenaje que merece un héroe nacional de la talla de Pompeyo Magno ${ }^{55}$.

Otro punto que llama la atención es el vínculo entre el culto isíaco y la abstinencia sexual femenina que tratan varios autores. Las Elegías de Propercio (47-15 a. C.), mencionan la castidad que se exige a los seguidores del isismo. Cintia, su amante, ha consagrado a la deidad diez noches sin contacto carnal alguno ${ }^{56}$, lo que enfurecía al autor hasta el extremo de desear que perezcan los cultos nilóticos, un anhelo que el lector puede captar en la obra sin dificultades ${ }^{57}$. Ovidio habla de Isis, en Amores, como excusa que dan las mujeres a sus amantes para mantenerles a raya, negándoles el placer ${ }^{58}$. Esta imposición debió resultar muy molesta a todos aquellos que veían frustradas sus expectativas amatorias, sobre todo si el que se veía afectado por el precepto de marras no era devoto de la diosa. Sin embargo, este hecho contrasta con las acusaciones de adulterio, alcahuetería y prostitución que también pesaban sobre las sacerdotisas y fieles de Isis.

En relación con esto último, en las Sátiras de Juvenal se puede encontrar a la deidad egipcia en varias ocasiones desde la óptica tan particular de este autor. Entre sus dardos envenenados tilda a Isis de chismosa ${ }^{59}$, refiriéndose a la acusación general de que las sacerdotisas de la diosa eran meras celestinas que cedían estancias de los iseos para encuentros nocturnos; también transmite información sobre la costumbre de los sacerdotes de Isis de arrastrarse sobre sus rodillas hasta hacerlas sangrar ${ }^{60}$, entre otros datos de menor trascendencia. También se alude al carácter del iseo, al igual que otros santuarios de distinta naturaleza, como lugar de citas en el que se prostituyen las mujeres $^{61}$. Clemente de Alejandría (150-217 d. C.), adopta sin reparos el tono agresivo que será la norma habitual en la práctica totalidad de la Patrología latina y, en $\mathrm{El} \mathrm{Pe}$ dagogo, ridiculiza la actitud de las mujeres durante las procesiones egipcias ${ }^{62}$. Como se puede ver la misoginia clásica también afecta a las devotas de Isis.

\subsection{DE ERRORES Y CRÍTICAS}

También encontramos errores que demuestran el profundo desconocimiento de algunos autores, que por muy ilustres que fueran sus ideas bien podían describir realidades de oídas o dando cosas por hecho. Así por ejemplo, Ovidio en Amores incluye un pasaje confuso y problemático en el que confunde a los sacerdotes galos de Cibe-

\footnotetext{
55 Lucan. VIII, 830-840; IX, 155-162.

56 Esta postura es muy común entre las mujeres devotas de Isis, que practicaban la castidad durante las fiestas de la diosa, algo que sacaba de quicio a sus maridos y amantes.

${ }^{57}$ Prop. II, 33A, 15-22; IV, 5, 33-34.

58 Ou. Am. I, 8, $73-77$.

59 Iuv. VI, 490.

${ }^{60}$ Iuv. VI, 520-535.

${ }^{61}$ Iuv. IX, 20-25.

62 Clem. Al. Paed. II, 35, 4.
} 
les con seguidores de Isis ${ }^{63}$, y por su parte el historiador Tácito (55-120 d. C.) comete una equivocación al afirmar en Germania que el pueblo de los suevos realizaba sacrificios en honor a Isis cuando, en realidad, las hecatombes estaban dirigidas a una divinidad germánica llamada Nertho ${ }^{64}$. El hecho de que se tratase de una divinidad matriarcal considerada la Madre Tierra por los germanos justifica, en cierta medida, el error cometido por este autor. No es mucho lo que sabemos de la religiosidad de los bárbaros en estos siglos, como de otros muchos aspectos relacionados con ellos, pero no parece nada probable que adoraran a Isis, al menos en un período tan temprano.

No está de más incluir algunos de los envites por parte de los sabios del cristianismo en estos siglos en los que dicha fe aún no había alcanzado su punto álgido. Clemente de Alejandría en Protéptico ataca a Isis y Serapis y afirma que sus templos serán derribados y quemados ${ }^{65}$, mientras que el apologista cristiano Tertuliano (160220 d. C.), incluye a la divinidad egipcia en su $A$ los gentiles, llegando a aparecer en dos ocasiones ${ }^{66}$. Sus referencias son siempre en tono de crítica, bien sea al mencionar las prohibiciones por parte del Capitolio de dioses egipcios como Serapis, Isis o Harpócrates (al cual parece confundir con Anubis, demostrando Tertuliano cierta ignorancia sobre el particular), como cuando condena el afeitado de la cabeza por motivos religiosos, algo que es característico de cultos como los de Saturno, Baco o Isis. En ambas se intuye el rencor hacia todo lo que huela a pagano que resulta característico de estos autores.

El abogado y apologista romano Marco Minucio Félix (150-270 d. C. ${ }^{67}$ ), en su Octavius, critica a la religión egipcia, sobre todo su zoolatría, en la que aprovecha para decir que Isis no es más peligrosa que un simple puerro picante ${ }^{68}$. También añade una relación de dioses aceptados como tales por sus méritos atribuida al hermeneuta Evémero, entre los que incluye a Isis Faria ${ }^{69}$; a ello hay que añadir una mofa en toda regla de la búsqueda de Isis, su cinocéfalo (Anubis) y sus sacerdotes de su hijo perdido, un rito anual que Félix estima estúpido y carente de sentido ${ }^{70}$. Es decir, son insultos en toda regla en contra de una religión que le resulta despreciable y digna del mayor de los oprobios. Esta será por lo general la postura imperante en la patrística de años venideros, tanto con relación al culto isíaco como al paganismo romano en su conjunto en el que Isis estaba ya más que integrada, labor de la que se encargarán con esmero autores cristianos del Bajo Imperio como por ejemplo Prudencio o Arnobio de Sicca, entre otros.

${ }^{63}$ Ou. Am. II, 13, 8-21.

${ }^{64}$ Tac. Germ. 9, 2. Sobre los germanos en Tácito, vid. Beare, 1964, pp. 64-76.

${ }^{65}$ Clem. Al. Protr. IV, 50, 3.

66 Tert. Apol. I, 10, 17-18; II, 17, 8.

${ }^{67}$ Los historiadores arrojan estas cifras como marco cronológico en el que pudo vivir Marco Minucio Félix, cuya cronología exacta se desconoce. Es decir, que en ningún momento se afirma que viviese ciento veinte años.

${ }^{68}$ Min. Fel. XXVIII, 7-9.

${ }^{69}$ Min. Fel. XXI, 1-3.

${ }^{70}$ Min. Fel. XXIII, 1. 


\subsection{OTROS PUNTOS DE INTERÉS}

Por su carácter misceláneo y por no encajar en ninguno de los cinco bloques anteriores, incluiremos aquí aquellas referencias que no encontraron cabida en las páginas anteriores. Ovidio incluye una breve anotación en Amores en la que invita a sus lectores a no tener miedo a lo que ocurre en el interior de los iseos ${ }^{71}$. Estos santuarios encuentran también su lugar en la novela Leucipa y Clitofonte de Aquiles Tacio (s. II d. C.), en la que una pareja de enamorados no solo se cita en el templo de Isis sino que se comprometen entre sí con la deidad egipcia a modo de testigo ${ }^{72}$. En La interpretación de los sueños de Artemidoro (s. II d. C.), ella aparece definida como diosa marina visible ${ }^{73} \mathrm{y}$, más adelante, este autor habla de cuatro divinidades procedentes de Egipto con un marcado carácter ctónico (Serapis, Isis, Anubis y Harpócrates ${ }^{74}$ ), que tienen unas cualidades excepcionales y son las responsables de garantizar el bienestar de todos aquellos fieles que se encuentran bajo su protección ${ }^{75}$.

En su Descripción de Grecia, el geógrafo e historiador Pausanias (s. II d. C.), nombra una cantidad muy detallada de emplazamientos de la Hélade en los que se encuentran iseos o santuarios consagrados a Isis y Serapis ${ }^{76}$, además de establecer en algunas ocasiones una relación de lo más curiosa entre la divinidad nilótica y los hijos de Zeus y Leto, es decir, Apolo y Ártemis. Este paralelismo en concreto no suele ser habitual, pero teniendo en cuenta que resulta lógico y coherente con los distintos procesos de sincretismo que tienen lugar en la antigüedad tampoco ha de resultarnos chocante en demasía. Ni que decir tiene que, para la disposición de los iseos tanto en el país que hoy llamamos Grecia como en el resto de los dominios del Imperio romano, contamos con un aliado mucho más valioso que Pausanias: la Arqueología. En cambio, no conviene menospreciar un testimonio que, junto al de Estrabón, es uno de nuestros principales referentes geográficos del mundo antiguo.

Por último, un par de anécdotas que relacionan a Isis con el mundo de los animales. Sexto Empírico (160-210 d. C.), filósofo griego y uno de los máximos referentes del escepticismo pirroniano, dice en uno de sus Esbozos Pirrónicos que es sacrílego sacrificar una oveja en honor de Isis ${ }^{77}$, mientras que Claudio Eliano (175-235 d. C.), en su recopilatorio de historia natural conocido como Historia de los animales, entre las muchas curiosidades que aparecen recogidas en sus páginas establece sendos nexos de unión entre Isis y animales tan diferentes como el buitre, el escorpión, la vaca, el áspid y el perro ${ }^{78}$, todo ello por medio de mitos o de hechos acontecidos en su propia contemporaneidad. De todos ellos la vaca sería la criatura que probable-

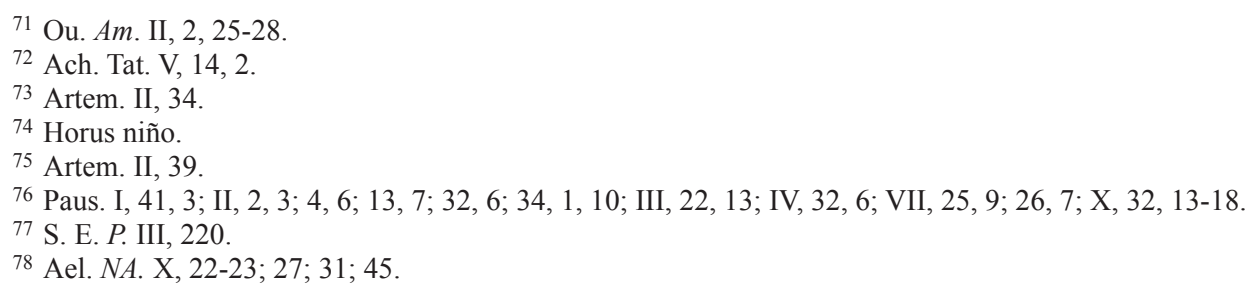


mente tenga un mayor grado de implicación con la divinidad nilótica, y buena prueba de ello es el hecho que fuese llamada por Ovidio vaca de Menfis o ternera de Faros, o la relación de este bóvido con Hathor e Ío, ambas vinculadas íntimamente con la diosa Isis.

\section{CONCLUSIONES}

La primera impresión que uno extrae de la lectura de estas referencias literarias, una selección lo suficientemente amplia como para considerarla representativa, es que la diosa recibe un tratamiento muy dispar y desenfocado por parte de los autores que hablan de ella ${ }^{79}$. La mayoría lo hace desde una posición desconfiada o abiertamente hostil. De hecho, solo Apuleyo de Madaura ofrece una narración tan sólida sobre elementos muy específicos e incluso ocultos ${ }^{80}$ del isismo como para suponer una estrecha vinculación del autor con el culto, de ahí la razón de ser de la hipótesis que muestra a Apuleyo como un iniciado y ferviente devoto de la divinidad nilótica ${ }^{81}$. Asimismo, se puede afirmar que Plutarco de Queronea ${ }^{82}$ sí que tiene ideas muy claras referidas a la religión isíaca, o al menos nociones básicas fundamentales que implican un acercamiento previo bien personal, bien por mediación de terceros. Del resto, cabe suponer que opinan sin más y que hay lagunas o carencias graves en sus referencias a Isis, carencias que se pueden ver acrecentadas por miedo a lo foráneo o lo desconocido, por inquinas personales o por intereses partidistas $^{83}$.

Si analizamos las principales cuestiones que son abarcadas en las citas compiladas, estas se pueden englobar de la siguiente manera: inutilidad del culto y lo ineficaces o ridículos que son sus rituales, críticas a sus seguidores, quejas relativas a la abstinencia sexual que el isismo imponía a sus devotas, asimilaciones con Ío, referencias a castigos impuestos por la divinidad a sus detractores y enemigos (principalmente la ceguera), recriminaciones a la ciudadanía romana por recibir con los brazos abiertos a deidades extranjeras, episodios y anécdotas de corte histórico (tanto arcaicos como contemporáneos a los autores) en los que la deidad desempeña un papel más o menos secundario; entre otras de menor importancia en las que por supuesto se incluyen algunos errores deliberados. El balance general es negativo, como puede apreciarse a simple vista, con un porcentaje muy superior de alusiones en tono peyorativo que de alabanza o elogio. Resulta obvio que la presencia de Isis entre los romanos no fue un

\footnotetext{
79 Antes hemos aludido a diversos tópicos erróneos y equivocaciones que así lo demuestran.

80 Vedados a lo no iniciados.

${ }^{81}$ Hidalgo de la Vega, 1986, pp. 9-10.

82 De hecho, es conocida la relación intelectual entre el autor griego y una sacerdotisa de Isis y de Osiris llamada Clea, a la que llega a dedicar dos de sus obras.

${ }^{83}$ Por ejemplo la defensa a ultranza de los cultos tradicionales romanos, la crítica a supersticiones de origen egipcio cuando el país del Nilo pasa a ser considerado como algo pernicioso por la alianza entre Cleopatra VII y Marco Antonio, o la apología del cristianismo llevada a cabo por los pensadores cristianos.
} 
camino de rosas, ya fuese por su condición egipcia, por las excentricidades inherentes a su culto o por motivos que se nos escapan ${ }^{84}$.

Es conveniente destacar que, con la posible excepción de Apuleyo de Madaura, no disponemos de noticias y escritos redactados por sacerdotes, seguidores o simpatizantes del culto isíaco ${ }^{85}$, por lo que la información que llega al lector contemporáneo es tan parcial y limitada como la inmensa mayoría de los testimonios literarios que nos ha legado el mundo antiguo. Reza el dicho que «la Historia la escriben siempre los vencedores», y en esta ocasión se ve claro una vez más: desde que Isis arriba a tierras itálicas, lejos de su Egipto natal, se topa con unas autoridades que no ven con buenos ojos todo cuanto la rodea, algo que se hace extensible a buena parte de los historiadores, filósofos, poetas y demás integrantes de la élite intelectual romana. Estos ignoran o critican un movimiento religioso que, al parecer, ni se conocía ni se quería conocer, una tendencia a la que luego vendría a sumarse el cristianismo. Se echan en falta algunos nombres en lo que respecta al listado de autores que aparece en este artículo, como pueden ser Cicerón, Séneca o el emperador Marco Aurelio, entre otros, lo que nos invita a dilucidar acerca del porqué de estas ausencias.

En clave de género, estos textos también ofrecen una oportunidad excelente para valorar el rol desempeñado por las mujeres en el seno de esta religión ${ }^{86}$. Tuviesen o no vinculación directa con el sacerdocio del culto, ocupaban cargos como el de las ornatrices, las encargadas de engalanar cada mañana la estatua de la diosa ante la que se postraban los fieles ${ }^{87}$. A modo de ejemplo vemos como Apuleyo, en su descripción del Navigium Isidis ${ }^{88}$ presenta a varias mujeres vestidas de blanco sosteniendo peines de marfil que estaban designadas para ataviar la estatua de la diosa y cuidar de su cabello. En el seno de las comunidades isíacas ellas podían desenvolverse con un mayor grado de libertad que en la religión oficial, y disponían además de la posibilidad de ocupar cargos de responsabilidad, algo que les estaba prácticamente vetado en la vida pública. Quizás este fue el principal aliciente para la iniciación de las devotas, aunque la mayor parte vería satisfechas sus inquietudes religiosas al mismo tiempo que se les concedía cierto protagonismo ${ }^{89}$. Cabe añadir que, en ningún momento, podemos hablar del isismo como una religión matriarcal o eminentemente feminina.

\footnotetext{
${ }^{84}$ Para entender mejor la cuestión, tal vez haya que tener en cuenta las apreciaciones de Arnaldo Momigliano sobre la extrañeza que lo egipcio causaba en Roma, contenidas en su libro La sabiduría de los bárbaros. Los límites de la helenización, F.C.E., México, 1988, pp. 15 ss.

${ }^{85}$ Quedan excluidos de esta afirmación los epígrafes y los papiros con letanías e himnos en honor de la diosa.

${ }^{86}$ Sobre la conexión habida entre las mujeres y sus familias en relación con la expansión de los cultos mistéricos, vid. Alvar y Rubio (et. al.), 1998.

${ }^{87}$ Heyob, 1972, pp. 81-110.

${ }^{88}$ El día 5 de marzo, en medio de una fiesta primaveral, se echaba al mar un navío con la imagen de la diosa simbolizando la apertura de la temporada de navegación. Es una de las festividades más conocidas del culto a Isis.

${ }^{89}$ Alvar, 1994, pp. 73-84.
} 
Como ya apuntamos, los autores cristianos como Clemente de Alejandría, Tertuliano, Hipólito de Roma o Marco Minucio Félix, no son más que la punta de la lanza de lo que estaría por llegar a partir del siglo IV, con una corriente cristiana mucho más agresiva y dispuesta a todo con tal de conseguir sus objetivos, entre los que por supuesto se encontraba el derrumbar la construcción política, religiosa e institucional del paganismo que, sin necesidad de ello, estaba pasando ya por una fase de manifiesta decadencia. La mejor defensa es un buen ataque y esa será la lógica a seguir hasta que la victoria del cristianismo en su vertiente nicena sea ya un hecho consumado. Algunos de los más famosos choques del cristianismo con la religión egipcia serán la destrucción del serapeo de Alejandría en el 392, el aplastamiento del foco de devoción isíaca en Menutis a finales del siglo V encabezado por Pedro el monje con el beneplácito del obispo Cirilo y la ya mencionada clausura del iseo de Filé en pleno siglo VI por parte de Justiniano. No pocos iseos y serapeos pasaron a convertirse en capillas e iglesias cristianas.

Antes de terminar, conviene señalar la importancia del conocimiento del culto a Isis, ya que cuanto más profundicemos en ese conocimiento, mejor capacitados estaremos para comprender al Imperio romano como un sistema integrador de culturas, muy dispares y distintas, dentro de un único aparato administrativo articulado en torno al mar Mediterráneo. El Mediterráneo no es solo una vía de comunicación o una ruta marítima idónea para el comercio, sino que facilita el desplazamiento de personas e ideas, con todo lo que ello supone. Estamos ante una divinidad de procedencia egipcia, que ha pasado por un filtro helenístico y luego se ha expandido por tres continentes, lo que no solo muestra la amplia difusión del isismo (aunque sea reinterpretado por la cultura grecorromana), también destaca la importancia de un país como Egipto aún reducido a la categoría de provincia; no en balde, la única provincia que no pertenecía al pueblo romano, sino que era propiedad del emperador. Esta importancia a distintos niveles (estratégica, económica, de abastecimiento, de comunicaciones, etc.), encuentra en el culto a Isis su manifestación religiosa más significativa.

Esta es, a grandes rasgos, la visión que arroja de Isis y su culto el acercamiento a las fuentes literarias grecolatinas que hemos recopilado en estas páginas. Lo sesgado de la perspectiva de estos autores resulta insuficiente para llegar a profundizar de manera exhaustiva en lo que verdaderamente tuvo que significar esta religión para los ciudadanos romanos. En consecuencia, hay que recurrir a la arqueología y a fuentes epigráficas o numismáticas, entre otras, para poder llegar a acercarnos un poco a una temática en la que, por encima de todo, sigue imperando una fuerte incomprensión. En conclusión, las fuentes literarias son irreemplazables para un buen desempeño de los estudios isíacos aunque, por si solas, nos condenan a desconocer la mayor parte de las aristas que conforman un poliedro casi infinito. Eso, y a descubrir tan solo los detalles que, sin sacrilegio, pueden revelarse a la inteligencia de los profanos, como bien diría un docto en la materia: Apuleyo de Madaura ${ }^{90}$.

\footnotetext{
90 Apul. Met. XI, 23, 7.
} 


\section{FUENTES}

AA. VV., Los gnósticos II, Introducción, traducción y notas de J. Monserrat Torrents, Madrid, 1983.

Apiano, Historia romana I, Introducción, traducción y notas de A. Sancho Royo., Madrid, 1980.

Apiano, Historia romana III, Guerras Civiles (Libros III-V), Introducción, traducción y notas de A. Sancho Royo, Madrid, 1985.

Apolodoro, Biblioteca, Introducción de J. Arce. Traducción y notas de M. Rodríguez de Sepúlveda, Madrid, 1985.

Apuleyo, El asno de oro, Traducción y notas de L. Rubio Fernández, Madrid, 1978.

Aquiles Tacio; Jámblico; Longo, Dafnis y Cloe. Leucipa y Clitofonte. Babiloníacas, Introducción, traducción y notas de M. Brioso Sánchez y E. Crespo Güemes, Madrid, 1982.

Arriano, Anábasis de Alejandro Magno (Libros I-III), Introducción de A. Bravo García. Traducción y notas de A. Guzmán Guerra, Madrid, 1982.

Artemidoro, La interpretación de los sueños, Introducción, traducción y notas de E. Ruíz García, Madrid, 1989.

Catulo; Tíbulo, Elegías. Poemas, Introducción, traducción y notas de A. Soler Ruíz, Madrid, 1993.

Claudio Eliano, Historia de los animales (Libros IX - XVII), Traducción y notas de J. M. DiázRegañón López, Madrid, 1984.

Clemente de Alejandría, El pedagogo, Introducción de A. Castiñeira Fernández. Traducción y notas de J. Sariol Díaz., Madrid, 1988.

Clemente de Alejandría, Protéptico, Introducción, traducción y notas de M. C. Isart Hernánde, Madrid, 1994.

Cornelio Tácito, Agrícola. Germania. Diálogo sobre los oradores, Introducción, traducción y notas de J. M. Requejo, Madrid, 1981.

Flavio Josefo, Autobiografía. Contra Apión, Introducción de L. García Iglesias. Traducción y notas de M. Rodríguez de Sepúlveda, Madrid, 1994.

Flavio Josefo, La guerra de los judios (Libros IV-VII), Traducción y notas de J. M. Nieto Ibáñez, Madrid, 1997.

Juvenal; Persio, Sátiras, Introducciones generales de M. Balasch y M. Dolç. Introducciones particulares, traducción y notas de M. Balasch, Madrid, 1991.

Luciano, Obras I, Traducción y notas de J. L. Navarro González, Madrid, 1992.

Luciano, Obras II, Traducción y notas de J. L. Navarro González, Madrid, 1992.

Luciano, Obras IV, Traducción y notas de J. L. Navarro González, Madrid, 1992.

Marco Anneo Lucano, Farsalia, Introducción, traducción y notas de A. Holgado Redondo, Madrid, 1984.

Marco Minucio Félix, Octavius, Lipsiae, 1992.

Pausanias, Descripción de Grecia (Libros I-II), Introducción, traducción y notas de M. C. Herrero Ingelmo, Madrid, 1994. 
Pausanias, Descripción de Grecia (Libros III-VI), Introducción, traducción y notas de M. C. Herrero Ingelmo, Madrid, 1994.

Pausanias, Descripción de Grecia (Libros VII-X), Introducción, traducción y notas de M. C. Herrero Ingelmo, Madrid, 1994.

Plutarco de Queronea, Obras morales y de costumbres VI, Introducción, traducción y notas de F. Pordomingo Pardo y J. A. Fernández Delgado, Madrid, 1995.

Propercio, Elegías, Introducción, traducción y notas de A. Ramírez de Verger, Madrid, 1989. Publio Ovidio Nasón, Amores. Arte de amar. Sobre la cosmética del rostro femenino. Remedios contra el amor, Introducción, traducción y notas de V. Cristóbal López, Madrid, 1989.

Publio Ovidio Nasón, Tristes. Pónticas, Introducción, traducción y notas de J. González Vázquez, Madrid, 1992.

Sexto Empírico, Esbozos pirrónicos, Introducción, traducción y notas de A. Gallego Cao y T. Muñoz Diego, Madrid, 1993.

Suetonio, Vidas de los doce césares (Libros I-III), Introducción de A. Ramírez de Verger. Traducción y notas de R. M. Acudo Cubas, Madrid, 1992.

Suetonio, Vidas de los doce césares (Libros IV-VIII), Traducción y notas de R. M. Acudo Cubas, Madrid, 1992.

Tertuliano, Apologético a los gentiles, Introducción, traducción y notas de C. Castillo García, Madrid, 2001.

\section{BIBLIOGRAFÍA}

J. Alvar, «La mujer y los cultos mistéricos: marginalidad e integración», en E. Hidalgo Blanco, G. Wagner y M. J. Rodríguez Manpaso (coords.), Roles sexuales: La mujer en la historia y en la cultura (1994) 73-84.

J. Alvar y R. Rubio (et. al.), «La religiosidad mistérica en el espacio familiar», Arys: Antigüedad, religión y sociedades 1 (1998) 213-226.

J. Alvar y C. Martínez Maza, «Cultos mistéricos y cristianismo», en J. Alvar (ed.), Cristianismo primitivo y religiones mistéricas (2007) 515-546.

R. A. Armour, Dioses y mitos del Antiguo Egipto, Madrid, 2006.

A. Baring y J. Cashford, El mito de la diosa. Evolución de una imagen, (trad. esp.), Madrid, 2005.

L. Bricault, Atlas de la diffusion des cultes isiaques (IVe siècle av. J. C. -IVe siècle apr. J. C), París, 2001.

L. Bricault, Les cultes isiaques dans le monde greco-romain, París, 2013.

W. Burkert, Cultos mistéricos antiguos, (trad. esp.), Madrid, 2005.

M. D. Donalson, The Cult of Isis in the Roman Empire. Isis Invicta, Nueva York, 2003.

P. Grimal, Historia Universal Siglo XXI Volumen 6: El helenismo y el auge de Roma. El mundo mediterráneo en la Edad Antigua II, (trad. esp.), Madrid, 1982.

P. Grimal, Historia Universal Siglo XXI Volumen 7: La formación del Imperio romano. El mundo mediterráneo en la Edad Antigua III, (trad. esp.), Madrid, 1982. 
J. Hani, Mitos, ritos y símbolos. Los caminos hacia lo invisible, (trad. esp.), Palma de Mallorca, 2005.

S. K. Heyob, The Cult of Isis Among Women in the Graeco-Roman World, Leiden, 1975.

M. J. Hidalgo de la Vega, Sociedad e ideología en el Imperio romano: Apuleyo de Madaura, Salamanca, 1986.

S. Husain, La diosa. Creación, fertilidad y abundancia. Mitos y arquetipos femeninos, (trad. esp.), Köln, 2006.

A. Lozano, «Asia Menor en época helenístico-romana. Panorama religioso», en J. Alvar (ed.), Cristianismo primitivo y religiones mistéricas, (2007) 115-156.

J. Padró, Historia del Egipto Faraónico, Madrid, 1996.

D. Plácido Suárez, «El culto de Isis en Atenas durante el Imperio romano», en R. Rubio Rivera (ed.), Isis, Nuevas Perspectivas: Homenaje al Prof. Álvarez de Miranda (1996) 2-11.

H. C. Puech, Historia de las Religiones Siglo XXI Volumen 5: Formación de las religiones universales y de salvación. Las religiones en el mundo mediterráneo y en el Oriente Próximo I, (trad. esp.), Madrid, 1982.

R. Radford Ruether, Rosemary, Goddesses and the Divine Feminine. A western religious history, California, 2005.

R. Turcan, Los cultos orientales en el mundo romano, (trad. esp.), Madrid, 2001.

R. E. Witt, Isis in the Ancient World, London, 1997. 